удК $81 ' 28$

\title{
T.A. Демешкина
}

\section{ТРАНСФОРМАЦИЯ ДИАЛЕКТНОЙ КОММУНИКАЦИИ ПОД ВОЗДЕЙСТВИЕМ СМИ}

\author{
Работа выполнена при финансовой поддержке Российского научного фонда (проект № 16-18-02043 \\ «Культура русского народа в диалектном языке и тексте: константы и трансформация»).
}

\begin{abstract}
Рассматривается влияние средств массовой коммуникации на организацию диалектной речи, проявляющуюся в смещении акцентов традиционного сельского общения. Изменения касаются, в первую очередь, набора речевых событий, характера прецедентных текстов, расширения лексического состава, функциональных сфер общения, смены традиционного кода передачи знаний и некоторых других. Анализируется степень влияния разных видов СМИ на традиционное сельское общение: радио, телевидения, газетных текстов.
\end{abstract}

Ключевые слова: диалект; коммуникация; трансформация; СМИ; высказывание.

Исследователи неоднократно фокусировали внимание на взаимном влиянии диалекта и литературного языка, выбирая разные векторы и аспекты такого влияния. Диалект неоднократно рассматривался и как источник пополнения словарного запаса современного литературного языка (см., например, работы А.И. Горшкова [1], Е.В. Вьюковой [2]), и как способ сохранения древних форм, утраченных в литературном варианте национального языка (работы Л.И. Шелеповой [3], Л.П. Дроновой [4] и др.).

Проблема вхождения диалектных слов в разные жанровые и стилевые разновидности языка с привлечением данных русского национального корпуса проанализирована в работе Н.Д. Голева и Н.Б. Лебедевой [5].

Не менее пристальному изучению подвергаются процессы, связанные с противоположным вектором влияния литературного языка на диалект. Исследователи отмечают утрату диалектных особенностей под воздействием школьного образования, литературы, а также различных видов СМИ и предлагают заменить термин «диалект» на «полудиалект» [5].

Вместе с тем в последнее десятилетие в мировой и отечественной науке активно формируется новая отрасль знания - региональная лингвистика, фокусирующая свое внимание на специфике региональной речи, включающей не только сельскую, но и городскую коммуникацию. Исследователи отмечают, что формируется новый лингвистический феномен - региональный язык как некое «переходное, неустойчивое языковое состояние, проявляющееся в определенных языковых ситуациях и находящееся между литературным языком и диалектом: литературный языкрегиональный язык - диалект» [6. С. 7; 7]. В ряде работ используется термин «региолект» $([8,9]$ и др.). А.И. Горшков употребляет в своих работах понятие «общий разговорный язык» и считает, что «полудиалект правильнее понимать как промежуточное явление не между территориальным диалектом и литературным языком, а между территориальным диалектом и общим разговорным языком» [1. С. 219].

Развитие новых научных направлений, в основе которых лежат идеи лингвокультурологического, когнитивного, дискурсивного анализа языковых явлений, актуализировало значимость диалекта как компонента национальной речевой культуры, без учета которого невозможно полное ее описание. Образцы описания диалекта в русле названных подходов про- демонстрированы в серии статей и монографий представителей томской диалектологической школы, рассматривающих диалект как выразитель национальной культуры, в котором более последовательно, чем в литературном языке, сохраняются и проявляются культурные и ментальные доминанты языковой картины мира [10]. Используемый диалектологами подход позволяет объяснить тот факт, что исчезновение диалектов, предсказанное исследователями еще в семидесятые годы прошлого столетия, так и не произошло. Так, широко известно высказывание Ф.П. Филина, который, со ссылкой на исследования диалектологов, писал о том, что «...местные говоры как цельные речевые единицы со своей особой системной организацией, известные по учебникам русской диалектологии и прежним диалектологическим описаниям, теперь уже не существуют» [11. С. 139].

В данной статье вектор анализа задан в направлении влияния средств массовой информации на организацию диалектного общения. В задачи входят рассмотрение зон и аспектов такого влияния, а также выяснение роли отдельных видов СМИ в трансформации традиционной сельской коммуникации. Работа выполнена на материале русских старожильческих говоров Среднего Приобья.

В качестве источника материала используются записи диалектной речи, хранящиеся в лаборатории общей и сибирской лексикографии Томского государственного университета, диалектные словари, составленные томскими диалектологами на материале русских старожильческих говоров Среднего Приобья, а также сборник текстов «Живая речь русских старожилов Сибири», составленный Е.В. Иванцовой по материалам экспедиций в село Вершинино [12].

В статье анализируется диалект как форма коммуникации, включающая лексику разной системной принадлежности (общерусскую, просторечную, диалектную). Для решения поставленной задачи наиболее репрезентативными источниками материала являются диалектные словари полных типов, а также записи диалектной речи, отражающие фрагменты устного текста.

Коммуникативное пространство рассматривается применительно к заданной проблематике как сфера коммуникации, включающая в себя место, время, адресата, адресанта, ситуацию общения, тематику, набор речевых жанров. Под взаимодействием комму- 
никативных пространств понимается взаимное проникновение элементов разных форм коммуникации, в результате чего происходит трансформация той или иной формы коммуникации.

Основной метод анализа, используемый для разработки решаемой проблемы, - метод научного описания, включающий приемы наблюдения, обобщения, контекстуального анализа, количественных подсчетов. Частично применяется метод дискурсивного анализа.

Влияние СМИ на диалектную форму коммуникации анализируется по нескольким параметрам.

1. Частотность лексем, обозначающих СМИ и функционирующих в диалектной коммуникации. Частотность употребления лексем, называющих разные виды СМИ, выявляется в рамках одного говора села Вершинино Томской области, на материале которого создано два словаря полного типа. Это «Вершининский словарь» в семи томах (гл. редактор О.И. Блинова) [13-15] и «Полный словарь диалектной языковой личности» в четырех томах (гл. ред. Е.В. Иванцова) $[16,17]$.

По данным «Вершининского словаря», степень распространенности в диалекте анализируемых лексем и их вариантов примерно одинакова. Так, телевизор в значении «телевизионный приемник» отмечен 37 раз, диалектный фонетический вариант телевизер - 34, по одному разу фиксируются келевизер и лексема телевидение. Слово газета в значении «периодическое издание, освещающее текущие события», отмечено 34 раза, газетка четыре, газеточка один, радио в значении «передача текстовых и музыкальных программ; вещание» и его вариант радиво 23 и 8 раз соответственно.

Как принадлежащий диалектной системе зафиксирован фразеологизм «сарафанное радио» в значении «слухи, сплетни, передаваемые из уст в уста». Приблизительно такая же картина наблюдается в речи одной языковой личности этого же села - Веры Прокофьевны Вершининой. Газета отмечено 27 раз, газетка 5 раз, телевизер / телевизор 8 / 28 раз, радио / радиво 14 / 41. Наличие вариантов и уменьшительно-ласкательных форм общерусских лексем, частотность употребления, вхождение во фразеологизмы - все это свидетельствует об их активном вхождении в диалектную речь.

Таким образом, можно сделать вывод о том, что все три вида СМИ (газета, телевизор, радио) являются объектами повседневной коммуникации и отражают зоны ее актуальности. Наиболее распространенными являются лексема «телевизор» и ее варианты. На втором месте по частотности находится лексема «газета». Несколько меньше фиксаций имеет слово «радио». Все это свидетельствует о различной степени предпочтительности в выборе того или иного источника информации, а также о разных предпочтениях в выборе досуга сельскими жителями в целом и отдельным человеком в частности. Так, например, материалы показывают, что основным источником информации для В.П. Вершининой является не газета и не телевизор, а радио, что позволяет рассматривать данные лексемы как одну из характеристик диалектной языковой личности.

Кроме того, в записях диалектной речи, сделанных в последние годы в селах Томской и Кемеровской областей, фиксируются лексемы Интернет и компьютер: А кто его знает, не знаю (про погоду). По этому, по интернету никак смотрят-то, чё-нибудь знают (Нестерово, Парабельский район, Томская область); По компьютеру посмотрит (внук), сразу сриcует и начинает вырезать, всё (Шестаково, Чебулинский район, Кемеровская область). Актуализация в речи данных лексем является показателем того, что происходит расширение словарного состава носителей диалекта за счет введения в коммуникацию слов, называющих разные виды и формы СМИ. Вместе с тем диалект, осваивая новые слова, адаптирует их к своим законам и к своей системе, что проявляется в образовании диалектных вариантов, грамматических форм, изменении и расширении лексической семантики слов литературного языка.

2. Место и статус анализируемых лексем в семантике диалектного высказывания. Лексемы, обозначающие разные виды СМИ, формируют объективный и субъективный «слои» семантики диалектного высказывания. В качестве материала анализа использованы записи диалектной речи, сделанные в селе Вершинино, поэтому материал не сопровождается локальными пометами.

Информация о видах СМИ эксплицируется в модусе высказывания и представляет собой ссылку на источник полученной информации, а также маркирует визуальный или аудиальный способ получения информации: Вчера по телевизору вон мы смотрели, у$y$, какие церква; Незнакомому солдату венок положили, цветы положили - по радио же слышали. Авторизационные смыслы формируют квалификативную часть модусной семантики. В диалектной коммуникации отмечается наличие положительной оценки СМИ с точки зрения достоверности. Средства массовой информации оцениваются в сельском общении как достоверный и авторитетный источник информации, который не подвергается сомнению. Это явление отражают высказывания диалектоносителей, содержащие прямую оценку достоверности информации, полученной из какого-либо вида СМИ: Я чё по радио передают, я всё верю. На это указывают и отсутствие маркеров персуазивности в анализируемых высказываниях, а также наличие в них средств экспрессивного утверждения: Клеш укусил и увозили. Маленько прекратили бы, помогло бы. Как не поможет? По радиву говорят. Нарушение этого правила воспринимается как отклонение от нормы: Таку заметку, совсем пустяковину - и в газету помещают.

Эти наблюдения свидетельствуют не только о том, что в диалектной коммуникации последовательно проявляется более высокая оценка литературной речи, книжной, официальной, письменной по сравнению с устной речью, но и о том, что также положительно оцениваются источники этой речи. Они определяют правила поведения, задают этические и эстетические нормы, способствуют повышению социального статуса того или иного человека: Я хотела в газету, штоб его похвалить за его уважение; Его в газету, в «Красну знамю» написали, как он работал.

Указание на СМИ как источник информации совмещается с обозначением субъекта - носителя рече- 
вого действия. Формы представления субъекта широко варьируются по шкале определенности / неопределенности. Наиболее частотная форма - это неопределенно-личная структура с главным членом-глаголом, обозначающим различные виды передачи информации: по телевизеру говорили, кажут, показывают, передают, по радио передают (передавали), писали же в газете. Субъект представлен как неопределенный, часто с семантикой обобщенности, и это позволяет сфокусировать внимание на самом факте передачи информации и усилить ее значимость.

Диктумное содержание, сопровождаемое подобной модусной рамкой, являет собой свод незыблемых истин, систему ценностей, стандартов, которых следует придерживаться. Наиболее часто в высказываниях такого типа содержатся приметы, рецепты, прогнозы: Кору крушины пью, вычитали на газетав <..> В газете было пропечатано про неё; По радио передают, иибко полезна она (трава) ото всего; Цыплятам нужна (скорлупа). Ну я не знаю, я по газетке читала, знаю, что нужна; $A$ вообще-то нынче в газете вычитала, что этот грыб есть нельзя; Без дров будут, газом отопляться. По радио передавали.

С ориентацией на СМИ формируются предпочтения в выборе одежды: Щас они (пальто) модны таки. Всё передают с Москвы всё: дублёнки, да всяки эти... польты да дохи да... В кине показывают платья широки, в телевизере тоже.

Наблюдения показывают, что происходит трансформация традиционного кода передачи информации в диалектной среде. Идут утрата знания и разрушение устной (обыденной) формы трансляции информации, играющей важную роль в сельском укладе жизни: Примет-то я не знаю. По радиву же говорят. А ласточки что? Счас их, ласточек, ни птичек, ничего нет.

Диктумное содержание включает в себя разные виды событийных пропозиций. Одной из частотных является реализация пропозиции восприятия, состоящей из предиката восприятия, субъекта и объекта восприятия. Лексемы - наименования разновидности СМИ занимают позицию объекта: Mы mеперь радио, телевизер слушаем; Вечер все телевизер смотрят; Цё-то он (сын) ичитат газету.

Кроме пропозиции восприятия распространенной является пропозиция действия, отражающая различные манипуляции с материальными носителями информации, представляющими собой конкретные предметы и включенными в повседневный быт. Наиболее часто в высказываниях актуализуется предметная семантика лексемы телевизор, что обусловлено техническими возможностями именуемого прибоpa, a также его большими габаритами, высокой ценой по сравнению с радио и газетой. Телевизор-предмет воспринимается как элемент обстановки, убранства дома и как показатель материального достатка и состоятельности и является основой пропозиции обладания: У них и телевизер, и комод, вся обстановка, стулья, столь. Шифонёр - одёэу хранят; Во всем селе уже телевизоры есть; Чё буду хвастаться телевизора не бувало. При оформлении пропозиции актуализуется временная оппозиция «прежде и те- перь», оцениваемая с точки зрения качества жизни: Все очень бедно жили: ни у кого ни телевизора.

Как предмет телевизор можно купить, сломать, починить. Все названные виды действия формируют пропозицию действия с различным количеством актантов и сирконстантов. Лексемы, обозначающие телевизор как прибор, занимают место объекта или субъекта: Давным-давно сгорел телевизер - всё-то ишо не белила; Это получила деньги... пятьсот рублей и говорю: добавлю две сотни, куплю телевизор цветной.

Меньшее количество манипуляций можно совершать с радио как предметом. Оно не имеет той материальной ценности, которой обладает телевизор, и не включается в пропозиции действия. Основная позиция лексемы радио - это вхождение в модусную часть высказывания. Обсуждению подлежат события, информация о которых получена аудиальным способом. События, которые попадают в зону коммуникации, являются разноплановыми и лежат преимущественно в бытовой сфере. Они касаются сельского хозяйства, аварий на дорогах и других новостей, передаваемых на радио: Ииь по радио передают, как авария быват, не дай бог; По радио передают на много намолачивают.

Газета в качестве материального носителя используется широко для хозяйственных нужд, и этим ее свойством обусловлено большое количество высказываний, в которых актуализованы пропозиции действия. Лексема газета замещает позицию средства действия либо приспособления, материала для выполнения действия: $A$ мать её по шиекам газетой хлопат; Я тебе говорила, газетой заверни (мясо).

Итак, анализ показал, что лексемы, обозначающие разные виды СМИ, формируют модусную и диктумную семантику диалектного высказывания. В модусе и в пропозиции восприятия актуализуется семантика источника информации, в диктумной части через пропозицию действия и пропозицию обладания реализуется предметная семантика лексем, называющих различные виды СМИ в Вершининском говоре. Присутствие СМИ в диалектной коммуникации определяет конкретное наполнение смысловой организации высказывания.

\section{3. Изменение коммуникативных характеристик} диалекта под воздействием СМИ. Воздействие СМИ на диалект как форму коммуникации проявляется по нескольким параметрам, определяющим специфику диалекта:

1. Расширяются тематика обыденного дискурса, а также набор речевых событий за счет обсуждения увиденного по телевидению, услышанного по радио, прочитанного в газете. Меняется тематическая доминанта бытовых разговоров. Наряду с традиционными темами: здоровье, погода, виды на урожай, обсуждение ситуаций и жизни односельчан - активно обсуждаются события социальной жизни, телесериалы, фильмы. Показательны в этом отношении названия устных текстов, представленные в сборнике, составленном Е.В. Иванцовой по материалам экспедиций в село Вершинино: «Выборы», «Интересны ихны картины», «Эти наши нещастны депутатишки», «Чечня». В центре обсуждения старожилов 
находятся события, получившие освещение в СМИ. Ссылки на источник информации выполняют роль авторизационного ключа, служат сигналом для начала беседы, приглашением к диалогу: Вчера-то смотрели (по телевидению) «Мушиина и женшина»?

2. Меняется характер прецедентных текстов за счет использования цитат, крылатых фраз, клише из рекламных передач. В проанализированном материале встретились тексты только из телевизионного источника: Вера, всё красиво, это как это, «Сникерс» ли хто ли он... ли «Твикс». А сын мой приехал и привёз эту «сладку парочку-то». Ой! Ну никакого вкуса нет! Ой. Вера. Милая моя, это за чёт око рекламу делают? (Вершинино, Томская обл.).

3. Возрастает количество элементов делового, официального дискурсов, что приводит к появлению разностилевых высказываний в рамках диалектного дискурса: Года три или четыре (назад) писали же в газете, что при перелете их (ласточек) сильно много погибло. Мороз-то был; Да, референдум тоже большо дело. Да хоть и... мы стоко и понимам, а просто...; У меня на столе не хватало, я на полу раскладывала всё, всякие издания, всяки-всяки издания, мне не хватало, ночью сижу, всё сорти... сортирую, чтобы к Новому году уже. К первому числу, была вся таблица сортировочна заготовлена. Гыт, одного набили Зубарева, говорят. Налупили, гыт, эти комоновць-то (ОМОН). Смешение стилей проявляется на лексическом уровне, когда в пределах одного высказывания употребляются разговорная лексика (налупить, стоко, всяки-всяки) и лексика официально-делового стиля (референдум, издания, сортировочная таблица и др.) и на уровне построения высказываний, что проявляется в наличии клише, штампов.
4. Формируется антропонимический и топонимический блок диалектной коммуникации, включающей личные имена, фамилии государственных, общественных деятелей регионального и российского масштаба: Неизвестных (депутат), я сльхала тоже, то ли по радио, то ли по телевизеру, да, да; А этот Андрей Мурашов (телеведущий) говорит: дискать, Кресс (губернатор области) уступал кажный час, приалашал всё; Так даже передавали по телевизеру ли... ну, по телевизеру передавали: Черномырдин пошёл в отставку - тридцать семь триллиона исчезли, да разе один Черномырдин? Чубайс от, Гайдар от - про всех говорили.

5. Происходит трансформация традиционного кода передачи информации в диалектной коммуникации, а также осуществляется формирование новых ценностных ориентиров и стандартов поведения (примеры были приведены выше).

Таким образом, анализ показал, что диалект как форма коммуникации подвергается определенной трансформации под воздействием СМИ. Изменения касаются набора речевых событий, характера прецедентных текстов, расширения лексического состава, функциональных сфер общения, смены традиционного способа передачи знаний и некоторых других параметров.

В то же время отметим, что диалект как адаптационная система «перерабатывает» элементы иной культуры в соответствии с целями, условиями коммуникации, спецификой адресата и адресанта, облекая полученную информацию в свойственные ему речевые жанры, сохраняя общий повышенный эмоционально-оценочный и экспрессивный фон речи, проявляемый в бытовых диалогах и полилогах.

\section{ЛИТЕРАТУРА}

1. Горшков А.И. Лекции по русской стилистике. М. : Лит. ин-та им. А.М. Горького, 2000. 272 с.

2. Вьюкова Е.В. Местные диалекты как источник пополнения словарного состава современного русского литературного языка (40-80-е гг ХХ в.): Методическая разработка по курсу «Русская диалектология». Томск, 1985. 27 с.

3. Шелепова Л.И. Источниковедческие возможности региональных этимологических словарей (на материале «Историко-этимолического словаря русских говоров Алтая») // Вестник Томского государственного университета. Филология. 2011 . № 3 (5). С. 65-70.

4. Дронова Л.П. Становление и эволюция модально-оценочной лексики русского языка: этнолингвистический аспект. Томск : Изд-во Том. ун-та, 2006. $256 \mathrm{c}$

5. Голев Н.Д., Лебедева О.Б. Лексика регионального словаря в Интернете // Язык, литература и культура в региональном пространстве : материалы Всерос. науч.-практ. конф., посв. пам. проф. И.А. Воробьевой / под ред. Л.И. Шелеповой. Барнаул : Изд-во Алт. ун-та, 2007. C. 9-22.

6. Коготкова Т.С. Русская диалектная лексикология. М., 1979.

7. Маслова В.А. Региональная лингвистика: проблемы и перспективы // Филологические науки. 2015. № 6. С. 3-8.

8. Герд А.С. Основные тенденции и параметры формирования региональных типов языка // Севернорусские говоры. 2014. № 13. С. 249264

9. Оглезнева Е.А. Дальневосточный региолект русского языка: особенности формирования // Русский язык в научном освещении. 2008. № 2. С. 119-136.

10. Томская диалектологическая школа: Историографический очерк / под ред. О.И. Блиновой. Томск : Изд-во Том. ун-та, 2006.392 с.

11. Филин Ф.П. Истоки и судьбы русского литературного языка. М., 1981.

12. Иванцова Е.В. Живая речь русских старожилов Сибири : сб. текстов. Томск, 2007. 104 с.

13. Вершининский словарь / под ред. О.И. Блиновой. Т. 2: Г-3. Томск : Изд-во Том. гос. ун-та, 1999. 317 с.

14. Вершининский словарь / под ред. О.И. Блиновой. Т. 6: Р-С. Томск : Изд-во Том. гос. ун-та, 2002. 451 с.

15. Вершининский словарь / под ред. О.И. Блиновой. Т. 7: Т-Я. Томск : Изд-во Том. гос. ун-та, 2002. 526 с.

16. Полный словарь диалектной языковой личности / под ред. Е.В. Иванцовой. Т. 1: А-3. Томск : Изд-во Том. гос. ун-та, 2006.355 с.

17. Полный словарь диалектной языковой личности / под ред. Е.В. Иванцовой. Т. 4: С-Я. Томск : Изд-во Том. гос. ун-та, 2012.363 с.

Статья представлена научной редакцией «Филология» 6 декабря 2016 г.

\section{THE TRANSFORMATION OF DIALECT COMMUNICATION UNDER THE MASS MEDIA INFLUENCE}

Vestnik Tomskogo gosudarstvennogo universiteta - Tomsk State University Journal, 2016, 413, 29-33.

DOI: $10.17223 / 15617793 / 413 / 4$

Tatyana A. Demeshkina, Tomsk State University (Tomsk, Russian Federation). E-mail: demeta@rambler.ru

Keywords: dialect; communication; transformation; mass media; statement. 
The article examines the impact of mass media on the organization of dialectal speech, which is manifested in a shift of emphasis of the traditional rural communication. The first part of the article presents a brief history of the issue relating to the mutual influence of the dialect on the literary language and the literary language on the dialect. The dynamics of research representations of dialect development and its place in the system of the national language is briefly analyzed. Names of scholars working in this direction are given. The problem definition and characteristics of the material are given after the review. The tasks of the article include consideration of areas and aspects of mass media influence on the dialect, as well as clarification of the role of different types of mass media in the transformation of traditional rural communication. The work is done on the material of Russian old resident dialects of the Middle $\mathrm{Ob}$ region. The main part of the work discusses the results. It has been identified that all three types of media (newspaper, $\mathrm{TV}$, radio) are the objects of everyday communication and reflect its relevance area. The most common lexeme is "TV" and its variants. The second highest frequency lexeme is "newspaper". The word "radio" is less frequent. These indicate the different degrees of preference in choosing sources of information, and the different preferences in the choice of leisure by villagers in general and an individual in particular. The role of the lexemes in the semantic organization of dialectal speech is analyzed. The changes of the communicative dialect characteristics under the influence of the media are identified. They include the expansion of the subjects of ordinary discourse, the changing nature of precedent texts, the increasing number of elements of media discourse, the formation of the anthropological and toponymic unit of dialect communication, the destruction of the information transmission code in the dialect. At the same time it is noted that a dialect as an adaptive system "recycles" the elements of a culture in accordance with the objectives, terms of communication, the specifics of the recipient and the sender, vesting information in its characteristic speech genres while retaining the overall increased emotional, evaluative and expressive background of speech in everyday conversations and polylogues.

\section{REFERENCES}

1. Gorshkov, A.I. (2000) Lektsii po russkoy stilistike [Lectures on Russian stylistics]. Moscow: Gorky Institute of Literature.

2. V'yukova, E.V. (1985) Mestnye dialekty kak istochnik popolneniya slovarnogo sostava sovremennogo russkogo literaturnogo yazyka (40-80-e gg. XX v.): Metodicheskaya razrabotka po kursu "Russkaya dialektologiya" [Local dialects as a source of replenishment of the vocabulary of modern Russian literary language (1940s-1980s): Methodological aid to the course "Russian dialectology"]. Tomsk: [s.n.].

3. Shelepova, L.I. (2011) Source study capabilities of regional etymological dictionaries (based on The Historical-Etymological Dictionary of the Russian Dialects of the Altai). Vestnik Tomskogo gosudarstvennogo universiteta. Filologiya - Tomsk State University Journal of Philology. 3 (15). pp. 65-70. (In Russian).

4. Dronova, L.P. (2006) Stanovlenie i evolyutsiya modal'no-otsenochnoy leksiki russkogo yazyka: etnolingvisticheskiy aspekt [Formation and evolution of the modal evaluative lexicon of the Russian language: ethno-linguistic aspect]. Tomsk: Tomsk State University.

5. Golev, N.D. \& Lebedeva, O.B. (2007) [Regional dictionary vocabulary online]. Yazyk, literatura i kul'tura v regional'nom prostranstve [Language, Literature and Culture in the regional space]. Proceedings of the conference. Barnaul: Altai State University.

6. Kogotkova, T.S. (1979) Russkaya dialektnaya leksikologiya [Russian dialect lexicology]. Moscow: Nauka.

7. Maslova, V.A. (2015) Regional linguistics: problems and perspectives. Filologicheskie nauki-Philological Sciences. 6. pp. 3-8. (In Russian). DOI: 10.20339/PhS.6-15.003

8. Gerd, A.S. (2014) Osnovnye tendentsii i parametry formirovaniya regional'nykh tipov yazyka [Major trends and parameters of the formation of regional types of language]. Severnorusskie govory. 13. pp. 249-264.

9. Oglezneva, E.A. (2008) Dal'nevostochnyy regiolekt russkogo yazyka: osobennosti formirovaniya [Far Eastern regional dialect of the Russian language]. Russkiy yazyk v nauchnom osveshchenii-Russian Language and Linguistic Theory. 2. pp. 119-136.

10. Blinova, O.I. (ed.) (2006) Tomskaya dialektologicheskaya shkola: Istoriograficheskiy ocherk [Tomsk Dialectology School: a historiographical essay]. Tomsk: Tomsk State University.

11. Filin, F.P. (1981) Istoki i sud'by russkogo literaturnogo yazyka [The origins and destiny of the Russian literary language]. Moscow: Nauka.

12. Ivantsova, E.V. (2007) Zhivaya rech' russkikh starozhilov Sibiri: sb. tekstov [Live speech of Russian old residents of Siberia: texts]. Tomsk: Tomsk State University.

13. Blinova, O.I. (ed.) (1999) Vershininskiy slovar' [Vershininsky Dictionary]. Vol. 2. Tomsk: Tomsk State University.

14. Blinova, O.I. (ed.) (2002) Vershininskiy slovar' [Vershininsky Dictionary]. Vol. 6. Tomsk: Tomsk State University.

15. Blinova, O.I. (ed.) (2002) Vershininskiy slovar' [Vershininsky Dictionary]. Vol. 7. Tomsk: Tomsk State University.

16. Ivantsova, E.V. (ed.) (2006) Polnyy slovar' dialektnoy yazykovoy lichnosti [Complete Dictionary of the Dialect of the Language Personality]. Vol. 1. Tomsk: Tomsk State University.

17. Ivantsova, E.V. (ed.) (2012) Polnyy slovar' dialektnoy yazykovoy lichnosti [Complete Dictionary of the Dialect of the Language Personality]. Vol. 4. Tomsk: Tomsk State University. 